\title{
New Exclusive Innovation Model of Obstetrical Pessary by Dr. Schneiderman: Preventtion and Treatment of Cervical Insufficiency and Habitual Abortion
}

Schneiderman $M^{*}$, Kalinina E, Yarotskaya E, Yavelsky V and Sukhikh G

Research Center for Obstetrics, Gynecology and Perinatology, Ministry of Health of Russia, Moscow, Russia

\section{Abstract}

The problem of habitual abortion is of clinical and social importance and a new model of obstetrical pessary can be successfully used for the treatment of patients with cervical insufficiency and habitual abortion.

\author{
Publication History: \\ Received: March 15, 2017 \\ Accepted: May 18, 2017 \\ Published: May 20, 2017 \\ Keywords: \\ Cervical insufficiency, Habitual \\ abortion, Obstetrical pessary, \\ Preterm birth
}

\section{Introduction}

For a number of years we have used pessaries produced in Russia, Belarus and Germany and we give a general description of the negative consequences of their application $[1,2]$.

Review of existing models of pessaries has identified a number of shortcomings in their design and adverse effects or complications during use. The most common of these are discomfort, pain, expulsion, vaginal irritation, bacterial vaginosis, actinomycosis and allergic reactions to latex inducing discontinuation. These adverse events are associated with inadequate form or material of a pessary. Excessive vaginal secretion and erosions are also the sequela of the inadequate quality of the material used, its density, susceptibility to microbial contamination and chemical degradation $[3,4]$. The main objective was therefore to design a new model of obstetrical pessary without the above-mentioned shortcomings.

Despite the success achieved in prevention and treatment of threatening and habitual abortion, the incidence of miscarriages remains stable and high enough. Thus, according to different authors, it ranges from $2 \%$ to $55 \%$, reaching $50 \%$ in the 1 st trimester.

The causes of miscarriage are numerous and varied. It can be associated with genetic, anatomical, endocrine, infectious, immune and thrombophilic factors. Uterine abnormalities were the main cause of habitual abortion in nearly $15 \%$ of women. Such abnormalities can be divided into 3 categories:

- Malformations of uterus (Müllerian duct anomalies);

- Abnormal uterine size and impaired blood supply caused by myoma, endometrial polyps and connective tissue (Asherman's syndrome);

- Cervical dysfunction.

Cervical insufficiency, manifesting with early cervical dilatation in pregnant women, often leads to preterm birth. There are various treatment methods: tocolysis, cervical cerclage, devices which provide mechanical support to insufficient cervix. Progressive dilatation of the cervical canal during pregnancy results in cervical shortening and softening, bulging of the fetal membranes into dilated cervical canal and finally deprivation of physiologic support for ovum, fetal membranes infection and rupture, and fetal expulsion from the uterine cavity. Vaginal placement of a medical pessary in a certain physiological position can prevent the above-mentioned complications. Mechanism of action of the pessary includes cervical compression by elastic walls of pessary's inner central ring and prevention of further cervical dilatation.

Nowadays there are dozens of obstetrical pessary models, but the study of existing models has identified a number of shortcomings in their design and complications during use.

The new model of obstetrical pessary by Dr. Schneiderman developed in the Research Center for Obstetrics, Gynecology and Perinatology of the Ministry of Health of Russia enables to prevent side effects common for these medical devices. New models are made of high-quality medical silicone of specific elasticity and density ensuring their optimal use.

A specific feature of the new model of obstetrical pessary by Dr. Schneiderman are four semi-circular symmetrically located notches on the outer surface of the ring and four symmetrical semi-circular bulges on the inner surface of the ring (Figure 1) [5,6]. The inner part of the pessary is made of silicon rubber with Shore A hardness 60, and the outer part is made of silicon rubber with Shore A hardness 10 or foam rubber, silicon rubber contains 2-4 mass silver nanoparticles (7).

Silicon rubber with hardness 10 or foam rubber used in the outer part cause minimal pressure on surrounding tissues without irritation, erosion and stretching.

"Corresponding Author: Dr. Michael Schneiderman, Research Center for Obstetrics, Gynecology and Perinatology, Ministry of Health of Russia, Moscow, Russia; E-mail: innamike@Imi.net

Citation: Schneiderman M, Kalinina E, Yarotskaya E, Yavelsky V, Sukhikh G (2017) New Exclusive Innovation Model of Obstetrical Pessary by Dr. Schneiderman: Preventtion and Treatment of Cervical Insufficiency and Habitual Abortion. Int J Gynecol Clin Pract 4: 129. doi: https://doi.org/10.15344/23944986/2017/129

Copyright: () 2017 Schneiderman et al. This is an open-access article distributed under the terms of the Creative Commons Attribution License, which permits unrestricted use, distribution, and reproduction in any medium, provided the original author and source are credited. 
Citation: Schneiderman M, Kalinina E, Yarotskaya E, Yavelsky V, Sukhikh G (2017) New Exclusive Innovation Model of Obstetrical Pessary by Dr. Schneiderman: Preventtion and Treatment of Cervical Insufficiency and Habitual Abortion. Int J Gynecol Clin Pract 4: 129. doi: https:/doi.org/10.15344/2394-4986/2017/129

Page 2 of 3

Besides silicon rubber with Shore A hardness 60 provides necessary pressure and limits axial and radial movements of the device.

Silver nanoparticles inhibit infectious diseases, eliminate bad odor and prevent inflammation of the vaginal mucosa.

\section{Methods}

A specific feature of the new model of obstetrical pessary by Dr. Schneiderman (Figure 1) are four semi-circular symmetrically located notches on the outer surface of the ring (due to these the pessary adjoins the vaginal walls and is retained reliably in a predetermined position without displacement). Another useful feature is four symmetrical semicircular bulges on the inner surface of the ring, which compress the cervix from four sides, preventing its opening (Figure 1) [8]

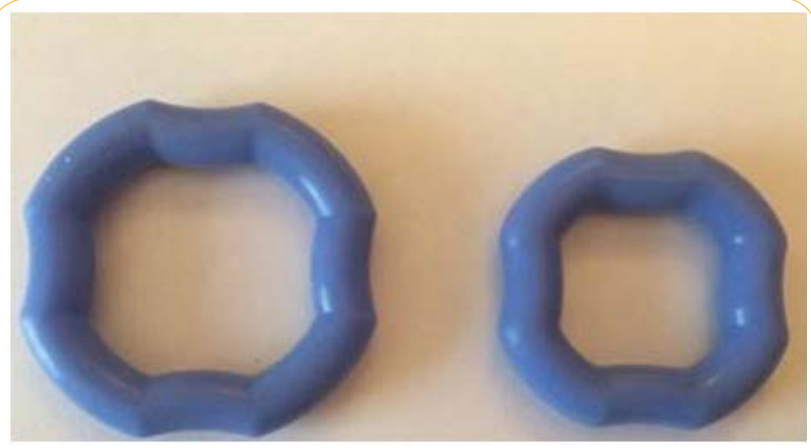

Figure 1: Obstetrical pessary by Dr. Schneiderman Model 1: four symmetrical semicircular slots on the external surface of the ring, four bulges on the internal surface of the ring.).

Absolutely new and significant advantage of the new model is its antimicrobial coating (miramistin, chlorhexidine, silver), preventing development of bacterial vaginosis which may impede use of a pessary [9].

The mechanism of prevention of cervical dilatation is based on cervical compression provided by the internal bulges and partial transfer of intrauterine pressure to the anterior wall of the uterus.

Application of pessary is easy and painless. Installation of pessary is possible in outpatient setting thus providing the economic feasibility of the treatment.

Installation of the pessary should be done by an obstetriciangynecologist. The doctor holds the pessary (its 2 opposite outer cuts) with two fingers, compressing it in vertical position, and introduces it into vagina up to its vault [10]. The pessary can be easily and painlessly removed from vagina (Figure 2). Then with the index finger the doctor ensures that the cervix comes to the central opening of the pessary, and the installation is accomplished.

The pessary is available in two sizes: for parous and nulliparous women. The appropriate choice cancels use of diaphragm in case if a pessary does not fit (Figure 4).

A new modified model has several structural differences from existing devices and reliably prevents the opening of the cervix in pregnant women with cervical incompetence as well as stress urinary incontinence. Installation of pessary is possible in outpatient setting thus providing the economic feasibility of the treatment.

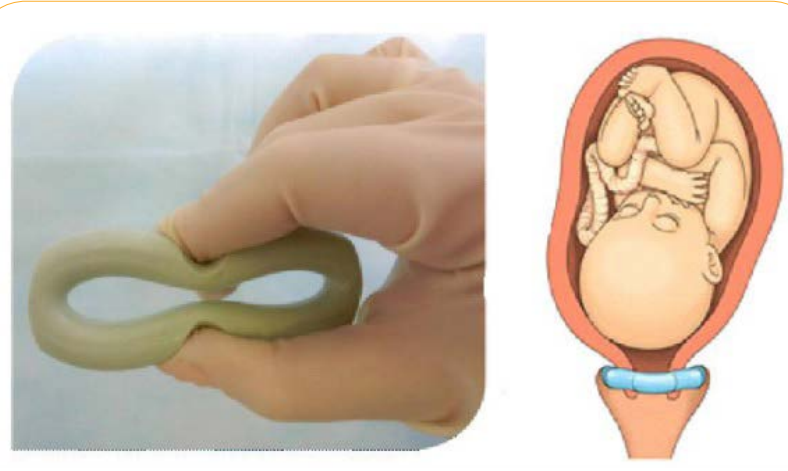

Figure 2: Installation of the pessary (on the left: squeezing pessary before insertion, on the right: position of the pessary on the cervix).

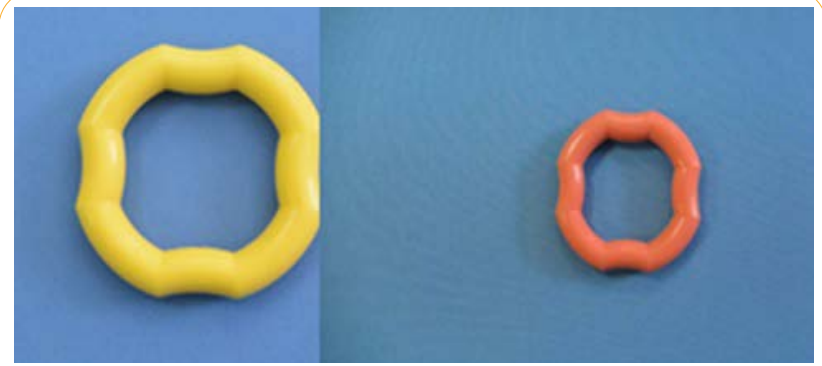

Figure 3: Pessaries for parous (left) and nulliparous (right) women.

A new modified model has several structural differences from existing devices and reliably prevents the opening of the cervix in pregnant women with cervical incompetence as well as stress urinary incontinence. Installation of pessary is possible in outpatient setting thus providing the economic feasibility of the treatment.

\section{Results}

The study of the new model of obstetrical pessary by doctor Schneiderman demonstrated its high reliability and efficiency. The subjects of the study were 208 women diagnosed with isthmic-cervical insufficiency, followed for four years. The criteria for initiation of the preventive treatment of patients at high risk of preterm birth were the following: cervical length $\leq 25 \mathrm{~mm}$ measured by ultrasonography and dilatation of cervical internal os more than $0,8 \mathrm{~mm}$ at the $15 \mathrm{th}-16 \mathrm{th}$ week of gestation and every 2 weeks on wards.

After installation of the pessary 4 patients (1.9\%) reported the sensation of "fullness" in vagina, which resolved in one-two days. 48 women had the history of miscarriage in the 2 nd trimester $(23,07 \%)$, 128 women $(61,5 \%)$ were nulliparous, 18 women $(8,6 \%)$ had previous operations on the cervix. Cervical length in 48 women $(23,07 \%)$ was less than $2.5 \mathrm{~cm}$. The pessaries were installed within the period 17.8 32.6 weeks of gestation. 192 women $(92.3 \%)$ delivered after the 34th week of gestation, 16 women $(7,6 \%)$ delivered before the 34 th week. The outcomes of all deliveries were successful. There was not a single case of development of pressure sores of the vaginal wall or bleeding associated with trauma to the vaginal mucosa. There were no uterine contractions before or after installation of the pessary, therefore no tocolysis was necessary. Removal of the pessary at the 37th -38 th weeks of gestation was painless and uneventful. The use of the new pessary allowed to maintain pregnancy in all 208 pregnant women to term. The analysis of pregnancy duration after treatment with pessary is demonstrated in Table 1. 
Citation: Schneiderman M, Kalinina E, Yarotskaya E, Yavelsky V, Sukhikh G (2017) New Exclusive Innovation Model of Obstetrical Pessary by Dr. Schneiderman: Preventtion and Treatment of Cervical Insufficiency and Habitual Abortion. Int J Gynecol Clin Pract 4: 129. doi: https:/doi.org/10.15344/2394-4986/2017/129

Page 3 of 3

\begin{tabular}{|l|l|}
\hline Age (average) & $20.4+1.2(18-43)$ \\
\hline $\begin{array}{l}\text { One miscarriage in the 2nd } \\
\text { trimester of pregnancy }\end{array}$ & $22(20.3 \%)$ \\
\hline $\begin{array}{l}\text { Two miscarriages in the 2nd } \\
\text { trimester of pregnancy }\end{array}$ & $10(9.25 \%)$ \\
\hline $\begin{array}{l}\text { Three miscarriages in the 2nd } \\
\text { trimester of pregnancy }\end{array}$ & $2(1.85 \%)$ \\
\hline Nulliparous & $34(31.4 \%)$ \\
\hline Preterm birth & $46(42.6 \%)$ \\
\hline Cervical surgery & $8(7.3 \%)$ \\
\hline Average cervix $(\mathrm{cm})$ & $2.0(1.6-2.5)$ \\
\hline
\end{tabular}

Table 1: Medical history data of patients (anamnesis) $(\mathrm{n}=208)$.

The majority of patients using pessaries delivered at 39 - 40 weeks though the pessaries were removed at $37^{\text {th }}-38^{\text {th }}$ weeks of gestation and gestation was prolonged by 8-16 days before labor. Urogenital infection associated with isthmic-cervical insufficiency was diagnosed in $6.4 \%$ of cases [10]. Bacterial vaginosis, candidiasis and opportunistic infections were mostly detected. Analysis of complications during pregnancy, delivery and postpartum period is shown in Table 2 .

\begin{tabular}{|l|l|}
\hline $\begin{array}{l}\text { Discomfort after installation of the pessary } \\
(1-2 \text { days })\end{array}$ & 4 women $(1,9 \%)$ \\
\hline $\begin{array}{l}\text { Interval from removal of the pessary to } \\
\text { delivery (days) }\end{array}$ & $10.5(8-12)$ \\
\hline Term of delivery (average, weeks) & $36.7(34-40.2)$ \\
\hline Delivery after the 34th week of gestation & 199 women $(95.6 \%)$ \\
\hline Delivery before the 34th week of gestation & 9 women $(4.3 \%)$ \\
\hline Duration of pregnancy prolongation (days) & $47(18.1-62.1)$ \\
\hline Cervical length $<2.5 \mathrm{~cm}$ & 48 women $(23,07 \%)$ \\
\hline Cervical length $>2.5 \mathrm{~cm}$ & 160 women $(76,9 \%)$ \\
\hline Dilatation of internal cervical os $(>0.8 \mathrm{~mm})$ & $112(53.8 \%)$ \\
\hline
\end{tabular}

Table 2: Terms of pregnancy at pessary installation (average, weeks).

\section{Discussion}

The article represents study results of the use of new exclusive models of obstetrical pessaries designed by Dr. Schneiderman in pregnant women with isthmic-cervical insufficiency and habitual abortion. Different aspects of the use of the new models of obstetrical pessaries have been investigated. The criteria for the treatment of patients at high risk of miscarriage or preterm birth were the following: cervical length $<25 \mathrm{~mm}$ and dilatation of internal cervical os more than 0.8 $\mathrm{mm}$. The use of the new pessaries enabled to prolong pregnancy by 47 (18.1-62.1) days.

The advantages of the new models of the obstetrical pessary are as follows:

1. Bulges on the internal surface of the ring preventing cervical dilatation in case of cervical insufficiency during pregnancy.

2. Stable fixation of the pessary in the vagina due to the external slots and lobes (preventing displacement or expulsion).

3. Reduced risk of lacerations of the vaginal mucosa due to minimal pressure to the vaginal wall.

4. Facilitated outflow of the vaginal discharge.
5. High comfort and easy installation.

6. Allergy free pessary.

7. Easy and painless removal of the pessary.

8. Elimination of symptoms of stress urinary incontinence.

9. Investigation of numerous cases evidences that the use of the new models of obstetrical pessaries provides support of pregnancy in patients with isthmic-cervical insufficiency.

\section{Conclusion}

The major challenge of prevention of preterm birth of pregnancy puts the task to manage isthmic-cervical insufficiency and recurrent miscarriage.

Application of the new model of obstetrical pessary considerably increases the chances of successful maintenance of pregnancy course untill term in women with cervical insufficiency and habitual abortion, reduces negative pregnancy outcomes and improves the quality of life of women with pelvic prolapse and stress urinary incontinence.

\section{Competing Interests}

The authors declare that they have no competing interests.

\section{References}

1. Goya M, Pratcorona L, Merced C, Rodó C Valle L, et al (2012) Cervical pessary in pregnant women with a short cervix (PECEP): an open-label randomized controlled trial. Lancet 379: 1800-1806.

2. Arabin B, Halbesma JR, Vork F, Hübener M, van Eyck J (2003) Is treatment with vaginal pessaries an option in patients with a sonographically detected short cervix? J Perinat Med 31: 122-33.

3. Kulakov VI, Serov VN, Sidel'nikova VM (2002) Prezhdevremennye rodytaktika vedenija s uchetom srokov gestacii [Premature labor-management tactics in view of gestation. Zhurnal akusherstva i zhenskih boleznej 2: 1318.

4. Sidel'nikova VM (2009) Nevynashivanie beremennosti [Miscarriage].

5. Schneiderman MG (2015) A new Russian model of obstetrical pessary for preventive care and treatment of cervical insufficiency and habitual abortion. Materials from the XVI Russian scientific forum "Mother and Child" 22-25

6. Schneiderman MG, Tetruashvili NK, Kan NY, Klimenchenkp NI, Kalinina EA, et al. (2015) A new Russian model of obstetrical pessary for preventive care and treatment of cervical insufficiency and habitual abortion. Materials from the VIII Regional scientific forum "Mother and Child" 73-74.

7. Schneiderman M (2014) Patent N142309 Obstetrical pessary Recorded into the state registry of utility models of the Russian Federation.

8. Schneiderman M (2014) A new Russian model of obstetrical pessary Материалы XV Всероссийского научного форума «Мать и дитя», Москва 23 сентября года.

9. Gorshkov AB, Schneiderman MG, Zhukova EE, Biber BL, Valetova NR, et al. Patent for the utility model N138859 Urogynecological device Authors:

Recorded into the state registry of utility models of the Russian Federation 28 February 2014

Materials from the XV Russian scientific forum "Mother and Child", Moscow, 23 September 2014.

10. Schneiderman MG, Gorshkov AV (2016) A new model of gynecological and obstetrical pessary. Mag Gynecol 18: 92-95. 